\title{
ÓLEOS ESSENCIAIS E VEGETAIS: MATÉRIAS-PRIMAS PARA FABRICAÇÃO DE BIOPRODUTOS NAS AULAS DE QUÍMICA ORGÂNICA EXPERIMENTAL
}

\author{
Catarina M. A. Bruno ${ }^{\mathrm{a}}$ e Márcia R. Almeida $\mathrm{a}^{\mathrm{a}, *, \odot}$

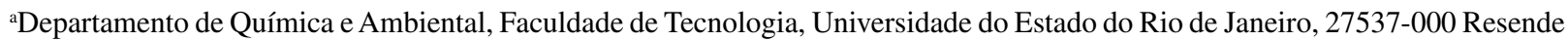 \\ - RJ, Brasil
}

Recebido em 03/01/2021; aceito em 26/01/2021; publicado na web em 18/02/2021

\begin{abstract}
ESSENTIAL AND VEGETABLE OILS: RAW MATERIALS FOR THE MANUFACTURE OF BIOPRODUCTS IN CLASSES IN EXPERIMENTAL ORGANIC CHEMISTRY. A schedule was prepared for three undergraduate classes for the discipline of experimental organic chemistry for obtaining bioproducts. As natural raw materials, lavender flowers and cinnamon peels were used to obtain hydrolates and essential oils (Class 1), coconut and avocado pulp to obtain vegetable oils and annatto seeds to obtain a natural dye (Class 2 ). Cosmetic bioproducts (Class 3), body emulsions similar to those found on the market, were obtained from the mixture of essential and vegetable oils and the addition of natural dye. The raw materials obtained can also be used in other classes of the discipline, complying with the principles of Green Chemistry. Essential oils, for example, can be used as samples for Thin Layer Chromatography (TLC) classes and vegetable oils for the production of biodiesel.
\end{abstract}

Keywords: vegetable oil; essential oil; bioproducts, natural dye; organic chemistry undergraduate classes.

\section{INTRODUÇÃO}

Os óleos essenciais (OE) são substâncias voláteis extraídas de plantas aromáticas, constituindo matérias-primas importantes para as indústrias medicinal, cosmética, farmacêutica e alimentícia. A Organização Internacional de Normalização (Do inglês: International Organization for Standardization - ISO) define os óleos voláteis como os produtos obtidos a partir de determinadas partes das plantas, através de técnicas de destilação, principalmente por arraste a vapor, bem como os produtos obtidos por prensagem dos pericarpos de frutos cítricos (Rutaceae). ${ }^{1}$

Em água, os óleos essenciais apresentam solubilidade limitada, mas suficiente para aromatizar as soluções aquosas, que são denominadas hidrolatos, produtos de interesse industrial. ${ }^{2}$ Os óleos essenciais ou voláteis, como também são conhecidos, apresentam em sua composição, principalmente, monoterpenos, sesquiterpenos, fenilpropanoides, ésteres e outras substâncias de baixo peso molecular. ${ }^{3}$ Já os óleos vegetais são produtos constituídos principalmente de glicerídeos de ácidos graxos de espécies vegetais. Podem conter pequenas quantidades de outros lipídios como fosfolipídios, constituintes insaponificáveis e ácidos graxos livres naturalmente presentes no óleo ou na gordura. ${ }^{4}$ Os ácidos graxos são ácidos carboxílicos de cadeia curta, média ou longa, geralmente não ramificada, com um número par de átomos de carbono entre 4 e 24 , e podem apresentar insaturações que referem-se basicamente ao isômero cis ou Z.,

Os óleos vegetais e as gorduras são constituídos principalmente por triacilglicerídeos, os quais são triésteres de glicerol com 3 moléculas de ácidos graxos. ${ }^{5,7}$ Segundo a Agência Nacional de Vigilância Sanitária (ANVISA), os óleos vegetais se apresentam na forma líquida à temperatura de $25^{\circ} \mathrm{C}$ e as gorduras vegetais se apresentam na forma sólida ou pastosa a $25^{\circ} \mathrm{C} .{ }^{4} \mathrm{São}$ ricos em ácidos graxos insaturados, já as gorduras apresentam maior percentual de ácidos graxos saturados em sua composição. As moléculas de ácidos graxos saturados apresentam rotação livre, devido à ausência de duplas ligações, o que favorece as interações intermoleculares que contribuem para maiores valores de ponto de fusão. ${ }^{5,8}$ Dessa maneira,

*e-mail: marcia.rosa@uerj.br a diferença entre óleos e gorduras depende apenas do ponto de fusão, ou seja, da composição química dos óleos e gorduras.

Os óleos essencias são utilizados como fixadores, fragâncias, aromas e condimentos por diferentes segmentos industriais, principalmente na indústria de cosméticos. ${ }^{2,9}$ Já os óleos vegetais têm uso difundido na indústria de cosméticos como ingredientes de bases, emolientes e hidratantes. ${ }^{10,11}$

Diante de suas propriedades, os óleos essenciais e vegetais são utilizados por muitas empresas brasileiras e estrangeiras na fabricação de bioprodutos em atendimento à demanda de consumidores preocupados com a preservação do meio ambiente e uso responsável dos recursos naturais, bem como na aquisição de formulações de origem vegetal (sem uso de matérias-primas de origem animal) e uso consciente dos ingredientes de origem natural. ${ }^{12}$

Segundo o Anuário da Associação Brasileira da Indústria de Higiene Pessoal, Perfumaria e Cosméticos (ABIHPEC), o Brasil é o quarto maior mercado consumidor global desse segmento, com $6,2 \%$ de fatia do mercado e um total de U\$D 30 bilhões em vendas ao consumidor no ano de 2018. Sendo os Estados Unidos da América o maior consumidor, com $18,3 \%$ do mercado consumidor mundial (U\$D 89,5 bilhões), seguido da China com 12,7\% (U\$D 62 bilhões) e Japão com 7,7\% (U\$D 37,5 bilhões). ${ }^{13}$

No Brasil, $41 \%$ da população tem interesse em maior variedade de produtos de beleza e cuidados pessoais com produtos de origem natural, principalmente os que contém em sua formulação insumos de nossa biodiversidade. ${ }^{12}$ Além disso, 29\% dos brasileiros preferem comprar de empresas com práticas sustentáveis e $50 \%$ dos consumidores optam por produtos com ingredientes de origem natural quando se trata de cuidados pessoais. ${ }^{12}$

Em atendimento a crescente demanda de bioprodutos pela população, principalmente no setor de cosméticos, e para tornar mais atrativa as aulas de Química Orgânica Experimental, sugeriu-se a fabricação de um bioproduto cosmético obtido de fontes naturais. Para tanto, foi desenvolvido um cronograma que abrange três aulas para a abordagem das técnicas de destilação simples, extração pelo método contínuo com Soxhlet e prensagem a frio, para a obtenção de um bioproduto a partir de insumos e matérias-primas obtidas de fontes naturais. 
A literatura apresenta diferentes propostas metodológicas para a utilização de produtos naturais nas aulas de Química Orgânica Experimental. ${ }^{14-20}$ Este trabalho propõe o uso de óleos essenciais, óleos vegetais e um corante natural para produção de bioprodutos, denominados óleos corporais bifásicos ou emulsões corporais, semelhante às encontradas no comércio. Segundo a ANVISA, a emulsão é a forma farmacêutica líquida de um ou mais princípios ativos que consiste de um sistema de duas fases com pelo menos dois líquidos imiscíveis e no qual um dos líquidos é disperso na forma de pequenas gotas (fase interna ou dispersa) no outro líquido (fase externa ou contínua). ${ }^{21} \mathrm{~A}$ emulsão corporal ou óleo corporal bifásico/ trifásico é formulado para obtenção de fases com propriedades dermatológicas diferentes ao contato com a pele. A presença de ácidos graxos na emulsão cosmética podem auxiliar na hidratação cutânea, ${ }^{22-24}$ já os óleos essenciais, além da fragância, podem conferir à emulsão diferentes propriedades biológicas, principalmente antifúngica e antibacteriana. ${ }^{25}$

\section{PARTE EXPERIMENTAL}

\section{Materiais e equipamentos}

Flores secas debulhadas de Lavandula dentata L. foram adquiridas no Lavandário de Cunha (SP) e sementes de Bixa orellana L. (urucum) foram coletadas de um espécime da região de Visconde de Mauá (RJ). As outras matérias-primas naturais como coco, abacate e cascas de canela, foram adquiridas em mercados da cidade de Resende - RJ. Os espectros de ultravioleta-visível (UV-Vis) foram obtidos em espectrofotômetro Nova Instruments modelo 1600UV, na região de 800 a $200 \mathrm{~nm}$, utilizando solução de $20 \mathrm{ppm}$ do extrato bruto, obtido das sementes de urucum, em clorofórmio e $0,1 \mathrm{mg} \mathrm{mL}^{-1}$ dos óleos vegetais analisados em clorofórmio. $\mathrm{O}$ volume dos solventes foi reduzido à baixa pressão em evaporador rotatório Buchi RE111 e banho-maria Buchi modelo B481. Os espectros de massas foram obtidos através de análises dos óleos essenciais em um cromatógrafo com fase gasosa CGS-2010 acoplado a um espectrômetro de massas (CG-EM) da Shimadzu, modelo QP2010 Ultra, equipado com analisador do tipo quadrupolo. Foi utilizada coluna capilar DB-1 ( $\mathrm{J} \& \mathrm{~W}$ ) de $30 \mathrm{~m} \times 0,25 \mathrm{~mm} \times 0,10 \mu \mathrm{m}$ de espessura de fase. O volume de injeção de amostra foi de 1,0 $\mu \mathrm{L}$ com divisão de fluxo de 1:20 e o hélio foi utilizado como gás de arraste a um fluxo de $1 \mathrm{~mL} \mathrm{~min}{ }^{-1}$. A temperatura inicial do forno foi de $60{ }^{\circ} \mathrm{C}$, com taxa de aquecimento de $5^{\circ} \mathrm{C} \mathrm{min}-1$ até $170{ }^{\circ} \mathrm{C}$, seguido por uma rampa de $10^{\circ} \mathrm{C} \mathrm{min}{ }^{-1}$ até $180^{\circ} \mathrm{C}$. O injetor foi operado a $280^{\circ} \mathrm{C}$ e a interface a $290^{\circ} \mathrm{C}$. O tempo total de corrida foi de 23 minutos e os espectros de massas foram obtidos a 70 eV. Foram utilizados para identificação das substâncias constituintes dos óleos essenciais analisados, os espectros de massas do banco de dados do Instituto Nacional de Padrões e Tecnologia (NIST 11 e NIST11s).

\section{Proposta metodológica}

Foi elaborado um cronograma para a realização de práticas em três aulas sequenciadas, com conteúdos que devem ser explorados na disciplina de Química Orgânica Experimental, para a obtenção de um bioproduto a partir de insumos naturais, conforme é apresentada na Tabela 1. O cronograma elaborado foi organizado para a realização de uma aula para a extração de óleos essenciais e/ ou hidrolatos de diferentes fontes naturais utilizando aparelhagem de destilação simples (hidrodestilação) (Aula 1), a segunda aula foi destinada à extração de óleos vegetais e corantes naturais utilizando aparelhagem de Soxhlet para a extração contínua (Aula 2) e a terceira aula para a fabricação do bioproduto, obtido a partir da combinação dos diferentes óleos essenciais, vegetais e corante natural, que abordou o preparo de soluções heterogêneas e emulsões (Aula 3) (Tabela 1).

Diferentes metodologias foram propostas para a obtenção de hidrolatos (Método 1), óleos essenciais (Método 2) e óleos vegetais para que o professor escolha a metodologia mais adequada à sua realidade no laboratório, em função do tempo do experimento/tempo de aula, disponibilidade de solvente e vidraria necessários para a produção dos bioprodutos. Todos os procedimentos experimentais apresentados na Tabela 1 são descritos a seguir.

\section{Extração de óleos essenciais}

Óleo essencial de Lavandula dentata $L$.

Método 1: Adicionaram-se $10 \mathrm{~g}$ de flores secas de Lavandula dentata L. e $250 \mathrm{~mL}$ de água destilada em balão de fundo redondo de $500 \mathrm{~mL}$ e empregou-se a hidrodestilação para extração do óleo essencial utilizando aparelhagem de destilação simples. Ao final de 2 horas de destilação foi obtido $97 \mathrm{~mL}$ de hidrolato de lavanda.

Método 2: Adicionaram-se $10 \mathrm{~g}$ de flores secas de Lavandula dentata L. e $250 \mathrm{~mL}$ de água destilada em balão de fundo redondo de $500 \mathrm{~mL}$ e empregou-se a hidrodestilação para extração do óleo essencial utilizando aparelhagem de destilação simples. Procedeu-se a destilação por 3 horas. Ao final desse procedimento foram obtidos $152 \mathrm{~mL}$ de hidrolato de lavanda.

Em seguida, o óleo essencial foi extraído do hidrolato com acetato de etila $(3 \times 50 \mathrm{~mL})$. A fase orgânica obtida foi seca com cloreto de cálcio anidro e concentrada em evaporador rotatório para obtenção do óleo essencial da lavanda. Foi obtido $1,0 \mathrm{~g}$ de óleo essencial. A fase aquosa foi descartada. Rendimento: $10 \% \mathrm{~m} / \mathrm{m}$.

Tabela 1. Cronograma de aulas de Química Orgânica Experimental para a produção de bioprodutos

\begin{tabular}{|c|c|c|c|c|}
\hline Aula & Conteúdo & Matéria-prima utilizada & Técnica empregada & Tempo \\
\hline \multirow{2}{*}{1} & \multirow{2}{*}{ Extração de óleos essenciais } & Flores de lavanda & \multirow{2}{*}{$\begin{array}{l}\text { Destilação simples } \\
\text { (Hidrodestilação) }\end{array}$} & $\begin{array}{l}2 \text { horas (Método 1) } \\
3 \text { horas (Método 2) }\end{array}$ \\
\hline & & Cascas de canela & & $\begin{array}{c}1 \text { hora (Método 1) } \\
2 \text { horas (Método 2) }\end{array}$ \\
\hline \multirow{3}{*}{2} & \multirow{3}{*}{$\begin{array}{l}\text { Extração de óleos vegetais e } \\
\text { corante natural }\end{array}$} & Polpa de abacate ${ }^{\mathrm{a}}$ & Prensagem a frio & 30 minutos \\
\hline & & Polpa de coco & \multirow{2}{*}{$\begin{array}{l}\text { Extração contínua } \\
\text { (Soxhlet) }\end{array}$} & $\begin{array}{c}2 \text { horas (Método } 1) \\
30 \text { minutos (Método 2) }\end{array}$ \\
\hline & & Sementes de urucum & & 2 horas \\
\hline 3 & Produção de bioprodutos & $\begin{array}{l}\text { Óleos essenciais, vegetais e } \\
\text { corante obtidos }\end{array}$ & $\begin{array}{l}\text { Preparo de soluções } \\
\text { heterogêneas }\end{array}$ & 30 minutos \\
\hline
\end{tabular}

${ }^{\mathrm{a}}$ Levar à estufa por 48 horas. ${ }^{\mathrm{b}}$ Repouso de 48 horas em refrigeração. 
Óleo essencial de cascas de canela comercial

Método 1: Colocaram-se $100 \mathrm{~g}$ de cascas de canela comercial, previamente cortadas, e $300 \mathrm{~mL}$ de água destilada em balão de fundo redondo de $500 \mathrm{~mL}$ e empregou-se a hidrodestilação para extração do óleo essencial utilizando aparelhagem de destilação simples por 1 hora. Foram obtidos $20 \mathrm{~mL}$ de hidrolato de canela.

Método 2: Colocaram-se $100 \mathrm{~g}$ de cascas de canela comercial, previamente cortadas, e $300 \mathrm{~mL}$ de água destilada em balão de fundo redondo de $500 \mathrm{~mL}$ e empregou-se a hidrodestilação para extração do óleo essencial utilizando aparelhagem de destilação simples por 2 horas. Foram obtidos $40 \mathrm{~mL}$ de hidrolato de canela.

Em seguida, o óleo essencial foi extraído do hidrolato obtido com acetato de etila ( $3 \times 15 \mathrm{~mL})$. A fase orgânica obtida foi seca com cloreto de cálcio anidro e concentrada em evaporador rotatório para obtenção do óleo essencial da canela. Foram obtidos $2,3 \mathrm{~g}$ de óleo essencial. A fase aquosa foi descartada. Rendimento: $2,3 \% \mathrm{~m} / \mathrm{m}$

\section{Extração de corante natural das sementes de urucum}

9,6 g de sementes de Bixa orellana $\mathrm{L}$. (urucum) foram submetidas a extração contínua com $350 \mathrm{~mL}$ de acetona utilizando-se extrator de Soxhlet, por um período de 2 horas. Em seguida, o volume de solvente contido no balão de extração foi reduzido em evaporador rotatório e foram obtidos $343 \mathrm{mg}$ de um sólido com coloração vermelhoalaranjado. Rendimento: $3,6 \% \mathrm{~m} / \mathrm{m}$

\section{Extração de óleos vegetais}

\section{Óleo de abacate}

Para extração de óleo de abacate foi empregado o método de prensagem a frio. Macerou-se $1,05 \mathrm{~kg}$ de polpa de abacate maduro. Em seguida, a polpa macerada ficou em estufa a $100{ }^{\circ} \mathrm{C}$ por 48 horas para perda de umidade. Foi obtido $222,2 \mathrm{~g}$ ( $22 \% \mathrm{~m} / \mathrm{m}$ de polpa seca $)$ de abacate desidratado. A massa de abacate residual foi envolta em um tecido de algodão e colocada entre duas placas metálicas. Com auxílio de um grampo de 5", a massa residual de abacate foi prensada manualmente para a obtenção de $18 \mathrm{~mL}(16,3 \mathrm{~g})$ de óleo de abacate. Rendimento: $7,33 \% \mathrm{~m} / \mathrm{m}$

\section{Óleo de coco}

Método 1: Utilizaram-se $104 \mathrm{~g}$ de polpa fresca de coco, previamente triturada em liquidificador industrial, para a extração contínua com $350 \mathrm{~mL}$ de etanol em aparelhagem de Soxhlet por 2 horas. Em seguida, o volume de solvente contido no balão de extração foi reduzido em evaporador rotatório e transferido para um funil de separação. A fase aquosa foi descartada e obtiveram-se aproximadamente 3,20 mL (3,0 g) de um óleo incolor com odor característico de coco. Rendimento: $2,8 \% \mathrm{~m} / \mathrm{m}$.

Método 2: Trituraram-se $123 \mathrm{~g}$ de polpa fresca de coco com auxílio de um liquidificador industrial. Em seguida, a polpa triturada foi colocada em um filtro de tecido de algodão para a separação do resíduo sólido e o leite de coco (extrato da polpa) contendo o óleo. O resíduo sólido foi descartado e o leite de coco obtido ficou em repouso por 48 horas em refrigeração $\left(8^{\circ} \mathrm{C}\right)$. O óleo de coco foi separado por decantação e foram obtidos $38 \mathrm{~mL}$. Rendimento: $28 \% \mathrm{~m} / \mathrm{m}$.

\section{Preparo de bioprodutos}

O fluxograma apresentado na Figura 1 descreve as etapas necessárias, em cada uma das aulas propostas, bem como as técnicas empregadas para obtenção dos óleos essenciais, hidrolatos, óleos vegetais e corante a partir das respectivas matérias-primas para a produção dos bioprodutos. As flores de lavanda debulhadas (Lavandula dentanta L.) e as cascas de canela (Cinnamomum zeylanicum) foram utilizadas como matéria-prima para obtenção dos óleos essenciais e hidrolatos, conteúdo abordado na aula 1 , a polpa das

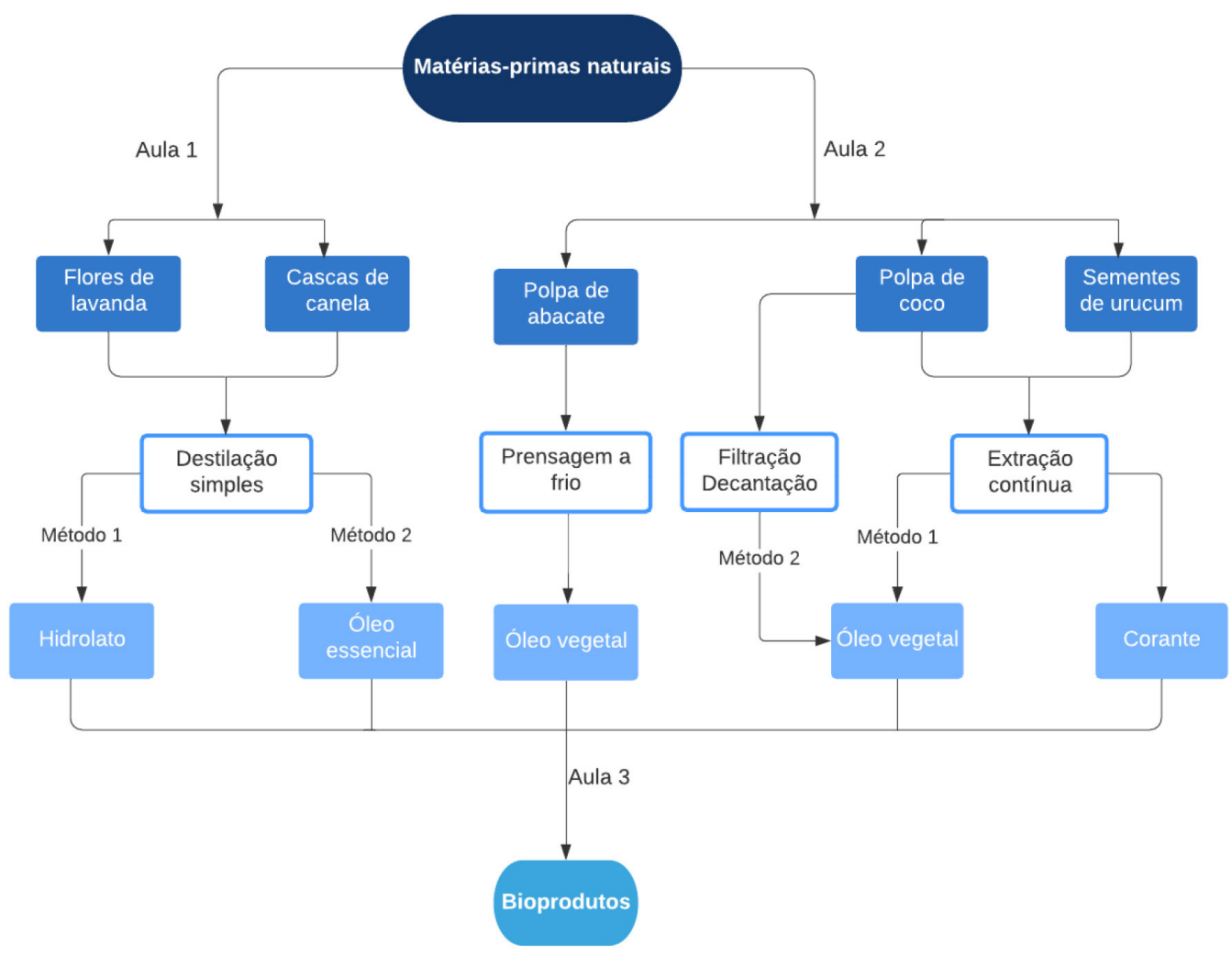

Figura 1. Etapas para a obtenção de bioprodutos a partir de matérias-primas naturais nas aulas de Química Orgânica experimental 
frutas de coco e abacate para extração dos óleos vegetais e, sementes de urucum para a extração do corante natural, conteúdo da aula 2. Foram obtidos diferentes bioprodutos, cinco emulsões corporais bifásicas, a partir da combinação dos óleos essenciais, hidrolatos e óleos vegetais como descrito a seguir.

\section{Com óleo de abacate}

Foram preparados três bioprodutos, denominados emulsões ou óleos corporais bifásicos, com composições diferentes a partir do óleo de abacate obtido. Para o preparo do óleo corporal, denominado 1 , foram adicionados a um tubo de ensaio com tampa rosqueável, $2,5 \mathrm{~mL}$ de óleo de abacate e $2,5 \mathrm{~mL}$ de hidrolato de canela. Para o preparo do óleo corporal 2, foram adicionados $2,5 \mathrm{~mL}$ de óleo de abacate, 2,5 mL de água destilada e gotas do óleo essencial de lavanda, a um tubo de ensaio. Já para a produção do óleo corporal 3, foram adicionados a um tubo de ensaio, $2,5 \mathrm{~mL}$ de óleo de abacate, $2,5 \mathrm{~mL}$ de hidrolato de lavanda e pequena quantidade do corante extraído das sementes de urucum.

\section{Com óleo de coco}

Foram preparados dois óleos corporais com composições diferentes a partir do óleo de coco obtido. Em um tubo de ensaio foi adicionado $1,5 \mathrm{~mL}$ de óleo de coco, pequena quantidade do corante bixina, 1,5 mL de água destilada e gotas de óleo essencial de lavanda para o preparo do óleo corporal denominado óleo corporal bifásico 4. Em um segundo tubo de ensaio, foi adicionado 1,5 $\mathrm{mL}$ de óleo de coco, pequena quantidade do corante bixina, e $1,5 \mathrm{~mL}$ de hidrolato de canela para o preparo do óleo corporal 5.

\section{RESULTADOS E DISCUSSÃO}

Como proposta metodológica, sugere-se utilizar duas espécies vegetais distintas para a obtenção dos óleos essenciais e dos óleos vegetais e dividir a turma para que sejam obtidas quantidades significativas dos dois tipos de óleos. Os estudantes deverão trabalhar em grupos e o professor deverá escolher a metodologia que seja mais adequada a sua realidade, levando em consideração o tempo de execução da prática (Tabela 1). Este trabalho apresenta opções de experimentos e metodologias em função de tempo e da disponibilidade de solventes no laboratório, bem como vidrarias para todos os grupos de estudantes. Poderão ser obtidos hidrolatos (Método 1) e/ou óleos essenciais de lavanda e canela (Método 2) (Figura 1) em função do tempo de aula e/ou disponibilidade de solvente para a etapa de isolamento do óleo essencial (Tabela 1). A extração do óleo de abacate e do óleo de coco empregando a metodologia 2 poderá ser demonstrativa ou realizada por apenas um grupo de estudantes, devido a necessidade de preparo prévio e o tempo de execução do experimento (Tabela 1, Figura 1). A extração do corante natural poderá ser realizada por apenas um grupo de estudantes, na segunda aula, e o restante dos grupos poderá extrair o óleo de coco, já que para as duas matérias-primas podem ser empregadas a extração contínua (Método 1), conforme apresentado na Tabela 1 e Figura 1.

Cada grupo de estudantes produzirá um bioproduto a partir do óleo essencial e vegetal de sua escolha, na terceira aula, conforme cronograma apresentado na Tabela 1. A adição de corante na formulação do bioproduto é livre. Sugere-se que a análise da composição química dos óleos essenciais por CG-EM, interpretação dos espectros de UV dos óleos vegetais e do corante sejam realizados, na terceira aula, após a obtenção do bioproduto (Figura 1, Tabela 1). Acredita-se que a compreensão e a associação entre o odor do bioproduto obtido e os resultados experimentais sejam facilitados após a obtenção do bioproduto. É interessante reservar partes das amostras de óleos essenciais e vegetais obtidos, em frascos separadamente, para verificação dos aromas individuais pelos estudantes e comparação com o bioproduto obtido. Além disso, essas amostras podem ser utilizadas em aulas posteriores para avaliar a memória olfativa ou em uma aula de Cromatografia em Camada Delgada (CCD).

Outros conteúdos como miscibilidade, volatilidade, origem e composição química da matéria-prima natural, bem como a estabilidade de emulsões e a função de tensoativos podem ser abordados. Além de temas transversais como o panorama da indústria de cosméticos no Brasil e no mundo e a legislação brasileira sobre insumos naturais para fabricação de cosméticos.

\section{Obtenção de óleos essenciais}

A extração dos óleos essenciais pode ser feita a partir de diferentes técnicas, como destilação por arraste a vapor, na maioria das vezes, prensagem a frio do pericarpo de frutos cítricos, hidrodestilação, enfleurage, extração com solvente e por fluidos supercríticos. ${ }^{2}$ Neste trabalho, optou-se pela técnica de hidrodestilação com o intuito de ensinar a montagem da vidraria de destilação simples, conteúdo obrigatório da disciplina de Química Orgânica Experimental, e seu uso para a extração de óleos essenciais. Foram escolhidos OE de lavanda e de canela por serem aromas conhecidos e devido ao emprego em diversos produtos alimentícios, de limpeza, higiene e cosméticos. Além disso, objetivou-se avivar a memória olfativa dos estudantes e despertar para os aromas utilizados em produtos do cotidiano.

A partir da característica turva do destilado obtido, hidrolato, pode-se discutir a solubilidade dos $\mathrm{OE}$ em água e a necessidade de etapa posteiror de separação e purificação. Neste trabalho, foram empregadas duas metodologias para uso dos óleos essenciais na composição do bioproduto proposto. Uso do hidrolato (Método 1) ou isolamento do óleo essencial do destilado obtido a partir da técnica de extração múltipla (Método 2). Esta, além de ser uma importante técnica na abordagem de separação e purificação de substâncias orgânicas, é eficiente e de fácil execução. ${ }^{26,27} \mathrm{Cabe}$ ressaltar a diferença de densidades dos solventes orgânicos, éter etilico e acetato de etila $\left(0,7138\right.$ e $0,9003 \mathrm{~g} \mathrm{~mL}^{-1}$ à $20{ }^{\circ} \mathrm{C}$, respectivamente $),{ }^{28}$ utilizados no processo de extração múltipla para definição das fases orgânica e aquosa. Após a extração, foi adicionado cloreto de cálcio anidro para remoção de gotículas de água provenientes da fase aquosa que ainda permaneciam na fase orgânica e, em seguida, a fase orgânica foi filtrada. Após filtração, a fase orgânica foi concentrada em evaporador rotatório para evitar degradação do óleo essencial devido ao tempo de contato do solvente com o óleo. O percentual do óleo essencial de lavanda obtido foi de $10 \% \mathrm{~m} / \mathrm{m}$ e para o óleo essencial de canela foi de $2,3 \% \mathrm{~m} / \mathrm{m}$ nas condições experimentais descritas. A obtenção do óleo essencial permite ao estudante determinar o rendimento do processo de extração, além da constatação de odor mais intenso quando comparado ao uso do hidrolato. De acordo com a literatura, o rendimento de óleo essencial de flores secas de espécies de Lavandula varia de acordo com o tempo de destilação $0^{29}$ de 0,5 à $6,8 \%$ e do $\mathrm{OE}$ de Cinnamomum zeylanicum varia de 0,2 a $2,0 \%$ quando obtido das cascas e de 0,7 a $1,2 \%$ nas folhas. ${ }^{30}$

\section{Óleo essencial de Lavandula dentata $L$.}

O perfil cromatográfico da amostra de óleo essencial de Lavandula dentata L. foi obtido com auxílio das bibliotecas do espectrômetro de massas, NIST11 e NIST11s. Como pode ser observado no cromatograma de íons totais (TIC) da Figura 2, a substância majoritária é o 1,8-cineol, correspondendo a $42 \%$ da composição do óleo, em seguida a cânfora com $28 \%$, a fenchona com $13 \%$ e o fenchol com $10 \%$ (Figura 7). Isso justifica o odor característico do óleo essencial obtido das flores de Lavandula dentata proveniente do Lavandário de Cunha (SP). 


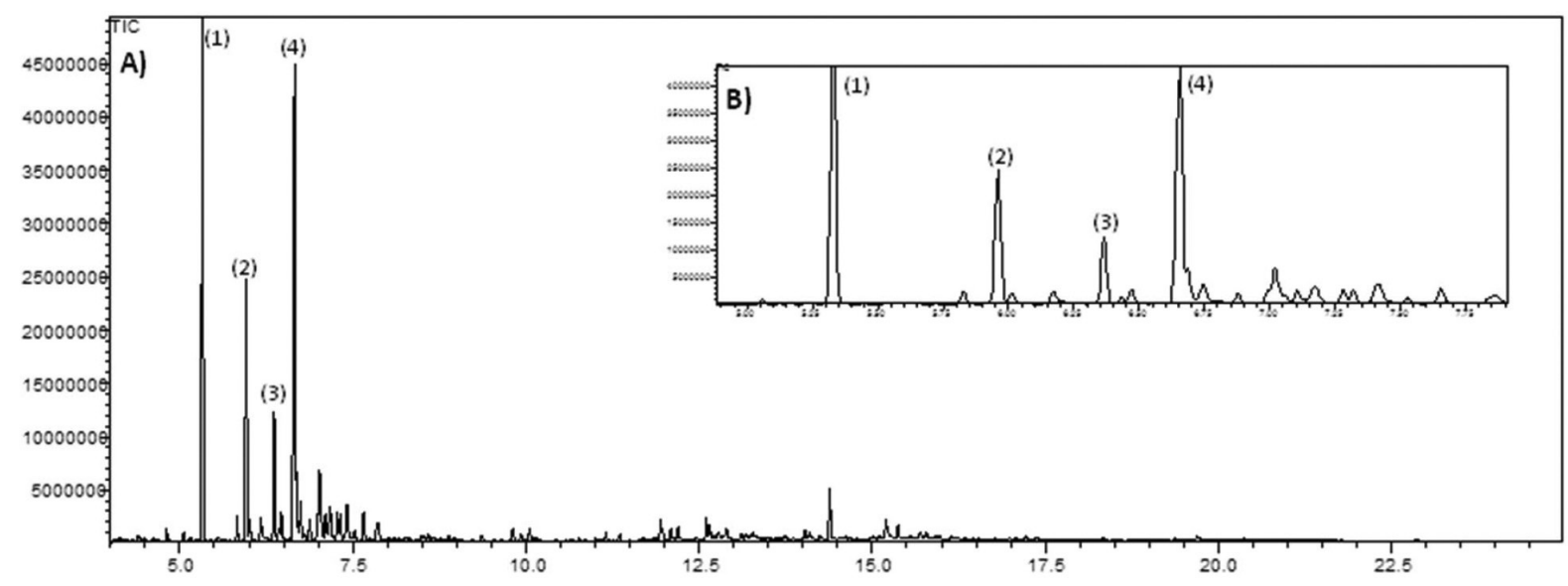

Figura 2. Cromatograma (A) e expansão do cromatograma (B) do óleo essencial de Lavandula dentata L. Constituintes majoritários do óleo: (1) 1,8-cineol, $T_{R}: 5,3$ min ; (2) fenchona $T_{R}: 5,9$ min; (3) fenchol $T_{R}: 6,3$ min e (4) cânfora $T_{R}: 6,6$ min

O gênero Lavandula inclui cerca de 39 espécies $^{31}$ e a Lavandula dentata, conhecida na Europa como lavanda selvagem francesa, é a variedade mais difundida em solo brasileiro, com destaque para o lavandário de Cunha em São Paulo e o Le Jardim Parque de Lavanda, em Gramado - RS. É uma espécie rica em 1,8-cineol (Figura 7), sendo esse o componente majoritário. ${ }^{32,33}$

A lavanda pertence à família Lamiaceae, e apesar de ser nativa do Mediterrâneo, é cultivada ao redor de todo o mundo devido as suas propriedades medicinais, funções decorativas e o seu valor econômico. É produzida principalmente para obter grandes quantidades de óleo essencial de alta qualidade para perfumaria, cosméticos e indústrias farmacêuticas. ${ }^{34} \mathrm{~A}$ composição do óleo pode variar de acordo com o método de extração, origem e fatores ambientais. $^{2}$

\section{Óleo essencial de cascas de canela comercial}

O perfil cromatográfico do óleo essencial de canela obtido foi avaliado por CG-EM e observou-se o cinamaldeído (Figura 7) como constituinte majoritário, correspondendo a $79 \%$ do conteúdo do óleo essencial, seguido do acetato de $(E)$-cinamila $(5,8 \%)$ e 1,8-cineol (4,3\%). A canela (Cinnamomum zeylanicum) pertence à família Lauraceae originária do Sri Lanka (antigo Ceilão), de onde vem a origem do seu nome, e também é cultivada na América do Sul. ${ }^{35} \mathrm{O}$ OE da canela é muito usado na indústria farmacêutica e de alimentos como flavorizante, bem como na fabricação de perfumes contribuindo para o equilíbrio das misturas odoríferas. $\mathrm{Na}$ perfumaria ele confere um tom picante, seco e quente às colônias, fazendo desse elemento um importante ingrediente na fabricação de vários perfumes orientais amadeirados, além de possuir propriedades medicinais. ${ }^{36}$

O conjunto de práticas propostas para a obtenção de um bioproduto para a indústria de cosméticos pode ser obtido sem a necessidade de análises cromatográficas por CG-EM dos óleos essenciais utilizados como matérias-primas. Pode-se solicitar aos estudantes uma descrição odorífera a partir da memória olfativa de cada estudante ou por comparação através de odores característicos dos óleos essenciais e de amostras de substâncias padrão que constituem o $\mathrm{OE}$, ou ainda amostras de $\mathrm{OE}$ comerciais.

\section{Extração de corante natural das sementes de urucum}

A extração de corante de uma fonte natural teve como objetivo, nesse projeto, tornar o aspecto visual do produto final atrativo, além de utilizar um insumo natural com propriedades antioxidantes para a produção de um bioproduto de interesse da indústria de cosméticos.
O urucum, fruto da bixácea, tem como constituinte majoritário a bixina, corante natural de coloração vermelha que é usado pelos indígenas desde tempos remotos, ${ }^{35}$ e sendo uma referência para a história do Brasil, foi escolhido para dar cor ao óleo corporal elaborado neste projeto. O corante também é empregado para fins industriais, na formulação de bebidas, na panificação e em outras massas, em laticínios, embutidos, cosméticos, tintas, como protetor solar contra raios ultravioleta, entre outras. ${ }^{37}$

O corante natural foi extraído através do método de extração contínua por Soxhlet utilizando acetona como solvente orgânico polar seguindo metodologia descrita por Costa \& Chaves. ${ }^{19} \mathrm{O}$ método de extração contínua foi escolhido em função da economia de solvente, na eficiência do processo ${ }^{27}$ e por contemplar a ementa da disciplina de Química Orgânica Experimental.

Ao final da extração contínua, o volume de solvente acetona contida no balão de extração foi reduzido em rotaevaporador e $343 \mathrm{mg}$ do corante vermelho-alaranjado foi obtido. O rendimento do processo de extração foi de $3,6 \%(\mathrm{~m} / \mathrm{m})$, inferior ao descrito na literatura. ${ }^{19} \mathrm{~A}$ concentração de bixina encontrada foi de $1,64 \%$ $\mathrm{m} / \mathrm{m}$, e foi determinada a partir do espectro de UV-Vis do extrato de urucum, obtido das sementes (Figura 3), segundo a lei de LambertBeer, $\mathrm{A}=$ a.b.c. Sendo A a absorbância da solução do extrato em clorofórmio, lida no espectrofotômetro, c a concentração de bixina na solução $\left(\mathrm{g} \mathrm{L}^{-1}\right)$, b o caminho ótico $(1 \mathrm{~cm})$ e a o coeficiente de absorção da bixina em $\mathrm{CHCl}_{3}$ no $\lambda_{\max }$ de $470 \mathrm{~nm}$, sendo esse valor de $2826 \mathrm{~L} \mathrm{~g}^{-1} \mathrm{~cm}^{-1} .{ }^{19,38,39}$

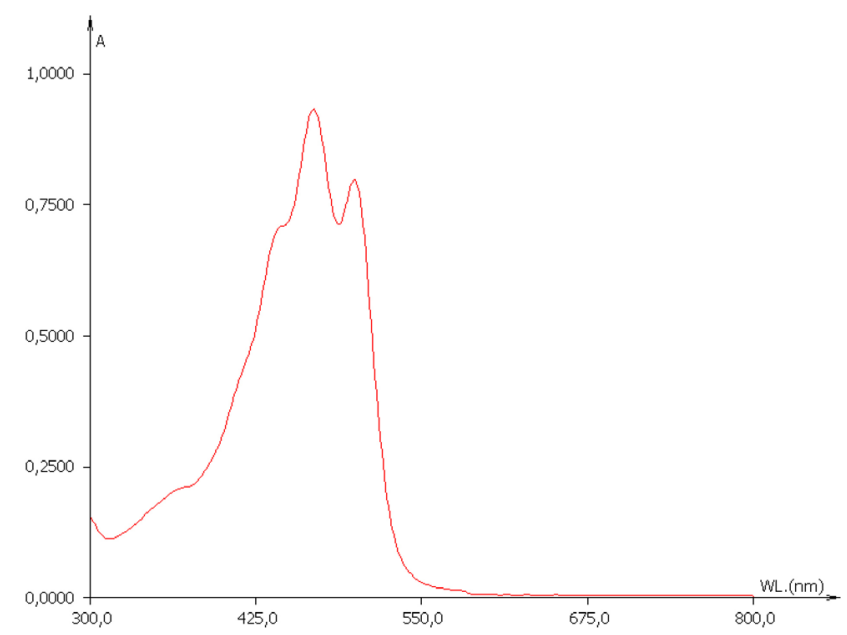

Figura 3. Espectro de absorção UV-Vis do extrato das sementes de Bixa orellana; Solvente: clorofórmio 
A bixina é o carotenoide majoritário encontrado nas sementes de urucum, correspondendo a $80 \%$ dos carotenoides produzidos e a $2,5 \%$ da massa das sementes desidratadas. ${ }^{40}$

Os isômeros cis (16Z) da bixina (Figura 7) e da norbixina estão naturalmente presentes nas sementes de urucum. Entretanto, quando submetidos a altas temperaturas, como nos processos de extração, são convertidos aos isômeros trans $(16 E)$, mais estáveis. Devido às diferenças estruturais, os isômeros apresentam propriedades físicas diferentes. A (16Z)-bixina não apresenta extensa solubilidade em óleos vegetais em virtude de sua conformação molecular e apresenta coloração alaranjada. Já a (16E)-bixina (Figura 7) é solúvel em óleos e apresenta coloração vermelha. ${ }^{40}$

A bixina apresenta coloração vermelha e é solúvel em óleo, enquanto que a norbixina, também denominada orelhina, éster da bixina, de coloração amarela, é solúvel em água. A solubilidade determina a aplicação dos corantes do urucum e a coloração que será obtida. A bixina, por exemplo, sendo lipossolúvel, é empregada como corante para laticínios, como em margarina, queijos, manteiga, e em outros produtos oleosos. Já a norbixina, sendo solúvel em água, é utilizada na fabricação de iogurtes, sorvetes, refrigerantes, cervejas e na formulação de alguns tipos de queijo. A bixina, apesar de ser um carotenoide, não possui atividade vitamínica A, entretanto, é um dos corantes naturais mais estáveis. ${ }^{37}$

\section{Extração de óleos vegetais}

\section{Óleo de abacate}

$\mathrm{O}$ abacate (Persea americana Mill.), pertencente à família Lauraceae, possui de 1 a $3 \%$ de proteína, de 5 a $35 \%$ de óleo e 3 a $8 \%$ de açúcar na polpa ${ }^{41}$ Do peso total do fruto, aproximadamente $70 \%$ corresponde à polpa e nela é encontrado elevado teor de óleo. ${ }^{42}$ O óleo de abacate é rico em ácidos graxos insaturados, cerca de 60 a $84 \%,{ }^{41}$ como os ácidos oleico (C18:1), linoleico (C18:2), palmitoleico (C16:1) e linolênico (C18:3). O ácido oleico (Figura 7) é o constituinte majoritário $(36-72 \%)^{43,44}$ e quantidades apreciáveis de vitaminas hidro e lipossolúveis (E, B, C e pró-vitamina A) e de constituintes minerais (fósforo, magnésio e potássio) são encontrados no óleo. ${ }^{41,43}$

O óleo de abacate se destaca por seu elevado nível de matéria insaponificável (1 a 4\%) quando comparado a outros óleos vegetais. ${ }^{45}$ As substâncias insaponificáveis são insolúveis em água e não susceptíveis a transformações químicas por reações de saponificação. Os principais componentes da fração insaponificável são os esteróis, álcoois alifáticos e terpênicos, hidrocarbonetos terpênicos, tocoferóis e outros compostos, com destaque para o $\beta$-sitosterol. ${ }^{43,46}$

A fração insaponificável do óleo de abacate é responsável por propriedades regenerativas da epiderme. Devido a fácil absorção na pele, o óleo de abacate é usado como veículo de substâncias medicinais; bem como fixador de perfumes. Também forma facilmente emulsões, por isso é usado para fabricação de sabões finos. ${ }^{44} \mathrm{~A}$ indústria de cosméticos utiliza tanto o óleo de abacate bruto ou semi-refinado como o óleo refinado, já a indústria farmacêutica utiliza o óleo semi-refinado e a alimentícia, o óleo refinado. ${ }^{43}$

Para extração do óleo do abacate foram escolhidos frutos no estágio maduro, devido aos teores elevados de óleo, ${ }^{43}$ e empregouse a técnica de prensagem a frio. $\mathrm{O}$ teor de umidade na polpa fresca varia de 64 a $85 \%$, e quando elevado, pode afetar o rendimento do processo de extração do óleo. ${ }^{42,47}$ Por esse motivo, foi necessária a etapa de secagem do fruto antes da prensagem. Nesse trabalho, o teor de água encontrado na polpa de abacate analisada foi de 78\%, já o teor de óleo na polpa seca foi de 7,33\% $\mathrm{m} / \mathrm{m}$. Cabe ressaltar que o baixo rendimento se deve ao uso de prensa manual improvisada e ao tempo de execução do experimento no período de aula.
A análise espectrofotométrica mostrou que o máximo de absorção para o óleo de abacate analisado foi $327 \mathrm{~nm}$, sendo que o espectro compreende toda região do ultravioleta A (UVA, 320-400 nm) (Figura 4A). As radiações UVA geram radicais livres oxidativos que são responsáveis pelo fotoenvelhecimento, doenças de fotossensibilidade e câncer de pele. ${ }^{48}$

A capacidade de absorção da radiação UVA pelo óleo de abacate deve-se as diferentes moléculas orgânicas ${ }^{49}$ que constituem as classes de fitoquímicos bioativos, como os carotenoides, vitaminas B, C e E, terpenoides, compostos fenólicos, além dos ácidos graxos insaturados e poli-insaturados. ${ }^{43,50}$

O óleo de abacate pode ser utilizado na produção de filtros solares, ${ }^{51-53}$ mas como absorve apenas na região UVA deve ser utilizado combinado a outros filtros para fornecer proteção completa da radiação ultravioleta. ${ }^{49}$

\section{Óleo de coco}

O óleo de coco é obtido da polpa do fruto da espécie Cocos nucifera L. pertencente à família Arecaceae. ${ }^{54}$ Os principais constituintes do óleo de coco são ácidos graxos, predominantemente os saturados, como capróico (C6), caprílico (C8), cáprico (C10), láurico (C12), mirístico (C14), palmítico (C16) e esteárico (C18). Dos ácidos graxos insaturados estão presentes, majoritariamente, o ácido oleico (C18:1), linoleico (C18:2) e palmitoleico (C16:1). ${ }^{55}$ Outros constituintes minoritários do óleo incluem os monoglicerídeos, diglicerídeos, fosfatídeos, ceras, pigmentos (carotenoides e clorofila) e esteróis (matéria insaponificável) como os tocoferóis, que inibem a oxidação das cadeias de ácidos graxos insaturados do óleo de coco. ${ }^{7}$

O óleo de coco é utilizado na indústria alimentícia, cosmética, na indústria de higiene e limpeza para a produção de sabão e detergente, na indústria textil para o pré-tratamento de fibras, na produção de surfactantes para a indústria do petróleo, na fabricação de tintas e vernizes e como biocombustível. ${ }^{55-57}$

O ácido láurico (Figura 7) é o constituinte majoritário do óleo de coco correspondendo de 40 a $50 \%$ de sua composição e, devido ao poder espumante, bactericida e por ser biodegradável é usado na indústria de higiene, de cosméticos e na fabricação de álcool. ${ }^{56}$ Já o ácido mirístico, o segundo constituinte principal (20\%), é usado em cosméticos como emoliente. ${ }^{58}$ Cerca de $70-80 \%$ da composição do óleo de coco corresponde a ácidos graxos de cadeia média, por esse motivo esse óleo é líquido, já que o nível de saturação determina a consistência da gordura em temperatura ambiente..$^{58}$

O óleo de coco pode ser obtido por diferentes metodologias, empregando processos seco ou úmido. Grande quantidade do óleo disponível comercialmente é obtido por processo seco a partir da copra (polpa seca do coco), que possui quantidade de óleo superior a $60 \% .{ }^{56}$ Neste trabalho, utilizou-se a polpa fresca do coco, uma vez que a técnica de secagem da polpa do fruto foi abordada na extração do óleo de abacate, como o objetivo de demonstrar aos estudantes que o teor de umidade interfere no rendimento do processo de extração de óleos vegetais. Além disso, foram empregadas duas metodologias distintas para a obtenção do óleo de coco (Método 1 e 2). No método 1 empregou-se a extração contínua à quente, para aprendizagem da técnica pelos estudantes, utilizando extrator de Soxhlet. Observou-se um baixo rendimento no processo de extração $(2,8 \% \mathrm{~m} / \mathrm{m})$ quando comparado a literatura. ${ }^{59}$ Esse fato pode ser explicado devido ao elevado teor de umidade da amostra, tempo e tipo de extração. $\mathrm{O}$ hexano é o solvente mais comumente utilizado para extração do óleo de coco, ${ }^{60,61}$ entretanto, neste trabalho optou-se por utilizar o etanol em atendimento aos princípios de química verde ${ }^{62} \mathrm{e}$ devido aos resultados de trabalhos publicados, ${ }^{59,63,64}$ que demostraram não haver variação significativa no rendimento da extração do óleo de coco utilizando etanol ou hexano como solvente. 

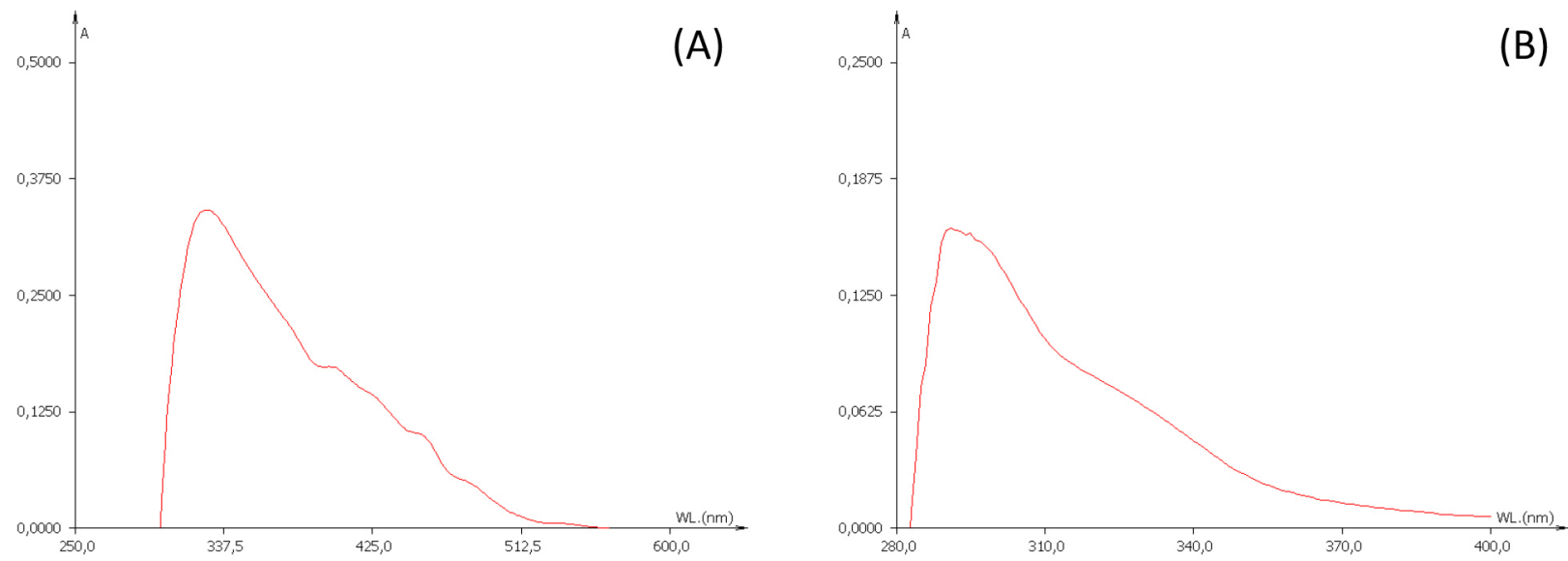

Figura 4. Espectro de absorção no UV-Vis do óleo de abacate (A) e óleo de coco (Método 1) (B); 0,1 mg mL-1 em clorofórmio

No método 2 empregou-se extração à frio para obtenção do óleo de coco. Nesse método, o extrato da polpa, o leite de coco, foi submetido a refrigeração $\left(8^{\circ} \mathrm{C}\right)$ por $48 \mathrm{~h}$ e o óleo foi separado por decantação e armazenado. ${ }^{65}$ Esse método é o mais simples e de baixo custo disponível para obtenção do óleo de coco. ${ }^{66,67}$ Foram obtidos $28 \% \mathrm{~m} / \mathrm{m}$ de rendimento no processo de extração do óleo de coco virgem, superior ao descrito na literatura. ${ }^{68,65} \mathrm{O}$ óleo obtido é assim denominado já que não houve uso de aquecimento durante o processo de extração. ${ }^{65,66}$

A análise espectrofotométrica do óleo de coco, obtido pelo método 1, em clorofórmio, mostrou que o máximo de absorção foi em $290 \mathrm{~nm}$, na região UVB (280-320 nm) do espectro, entretanto, também foi observada absorção na região do UVA $(320-400 \mathrm{~nm})$ (Figura 4B).

Foi observado um percentual de transmitância de 82 a $98 \%$ na região do ultravioleta A para o óleo de coco analisado. Esse resultado mostra que o óleo de coco absorve no máximo $18 \%$ da radiação UVA, já o óleo de abacate absorve cerca de 53\% (Figura 5), o que está de acordo com a composição química desses óleos vegetais e com os resultados da literatura. ${ }^{69,51}$ Sugere-se como atividade para os estudantes a obtenção e comparação dos espectros de transmitância dos óleos de coco e abacate na região do UVA para discussão de uso desses óleos como filtros solares.

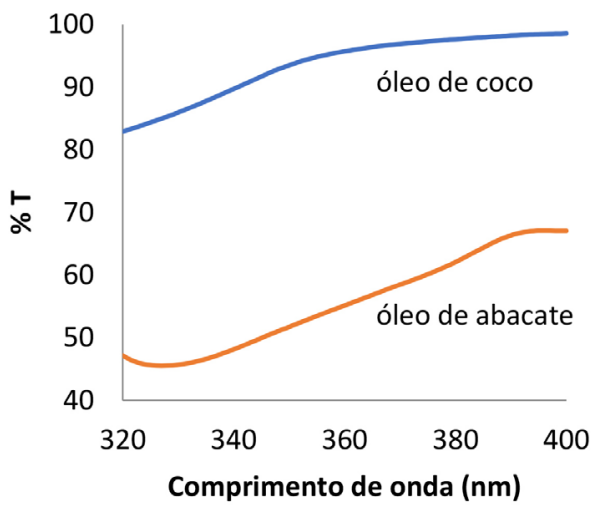

Figura 5. Espectro de transmitância dos óleos de abacate e coco na região do UVA

Embora atuem como filtros solares de origem natural, ${ }^{51-53}$ os óleos vegetais analisados absorvem parte da radiação compreendida na região do UVA e o óleo de coco absorve radiação UVB. Por esse motivo, devem ser combinados a outros filtros para fornecer proteção completa e eficiente contra a radiação ultravioleta. ${ }^{70,49}$

\section{Obtenção de bioprodutos cosméticos}

Foram obtidos cinco bioprodutos a partir da combinação dos óleos essenciais ou hidrolatos, de lavanda ou canela, com os óleos vegetais, de coco ou abacate, com adição de corante bixina. Todas as misturas realizadas seguiram a proproção de $1: 1 \mathrm{v} / \mathrm{v}$ de óleo vegetal e fase aquosa para comparação e definição do bioproduto com odor mais agradável.

Os bioprodutos obtidos foram denominados emulsões corporais ou óleos corporais bifásicos devido à composição química e imiscibilidade das fases orgânica e aquosa que os compõe. As emulsões podem ser observadas na Figura 6.
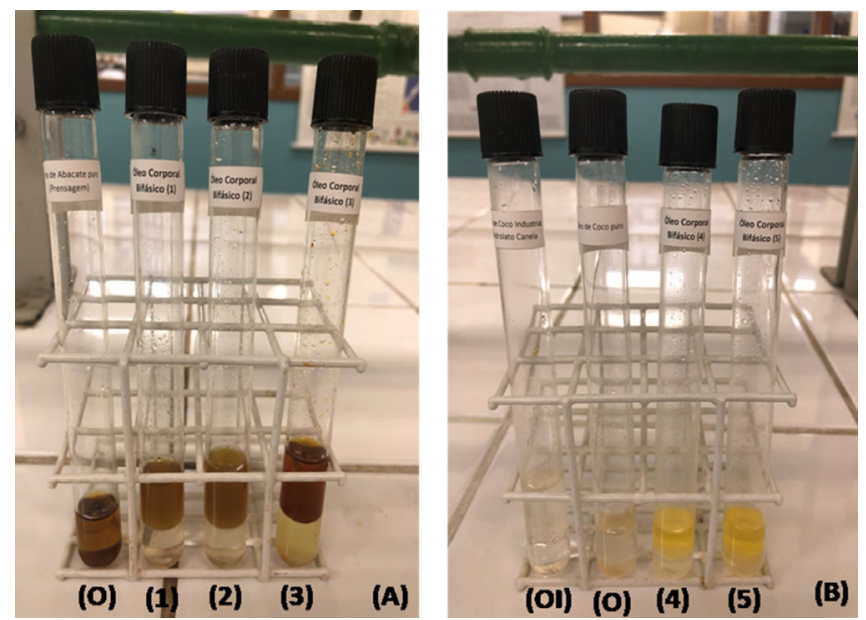

Figura 6. Bioprodutos obtidos a partir do óleo de abacate $(A)$ : (O) Óleo de abacate; (1) Óleo corporal bifásico 1; (2) Óleo corporal bifásico 2; (3) Óleo corporal bifásico 3. Bioprodutos obtidos a partir do óleo de coco (B): (OI) Óleo de Coco industrial; (O) Óleo de coco, (4) Óleo corporal bifásico 4; (5) Óleo corporal bifásico 5

É interessante discutir a composição e a diferença de densidade das fases orgânicas e aquosas para os bioprodutos obtidos, bem como a solubilidade da bixina, principalmente, na fase orgânica, como pode ser observado nos óleos corporais 3, 4 e 5 (Figura 6).

Sugere-se que as matérias-primas naturais, óleos vegetais extraídos, óleos essenciais e hidrolatos, também sejam armazenados em tubos de ensaio com tampa rosqueável para melhor comparação olfativa com os bioprodutos obtidos. Outra sugestão é aquisição de amostras comerciais de óleos essenciais e óleos vegetais para comparar com as matérias-primas extraídas nas aulas experimentais e guiar os estudantes no desenvolvimento sensorial. Neste trabalho 

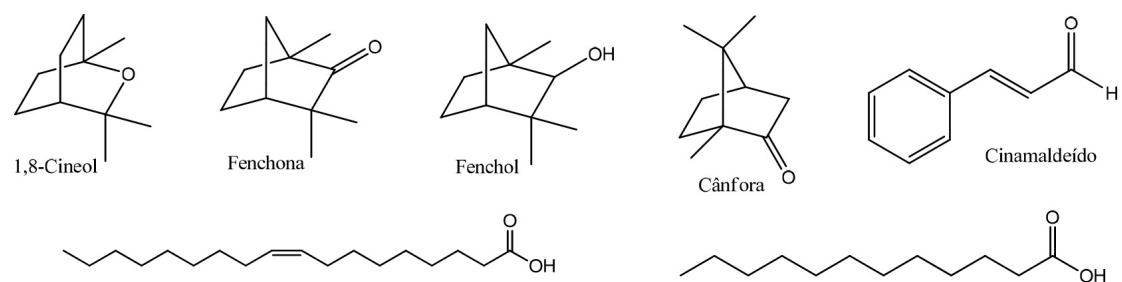

Ácido oleico (C18:1)
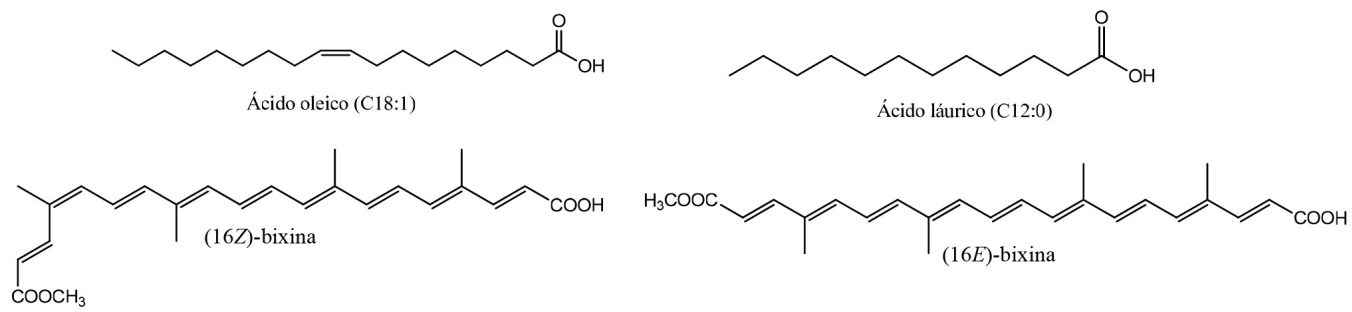

Figura 7. Constituintes majoritários das matérias-primas naturais utilizadas na fabricação dos bioprodutos

foi adquirido um óleo de coco comercial, denominado óleo de coco industrial. Observou-se odor mais agradável para o óleo corporal 5 (Figura 6B) quando comparado ao óleo corporal produzido a partir da mistura do óleo de coco industrial e hidrolato de canela (Figura 6B).

Todas as emulsões corporais produzidas apresentaram odores agradáveis e as composições com óleo de coco tiveram maior aceitação em relação ao aspecto visual devido à presença do corante bixina.

\section{CONCLUSÕES}

Esse trabalho propôs a obtenção de bioprodutos cosméticos obtido de fontes naturais nas aulas de graduação da disciplina de Química Orgânica Experimental. Foi apresentado um cronograma contemplando três aulas da disciplina abordando técnicas de destilação simples e extração pelo método contínuo com Soxhlet e por prensagem a frio, para a obtenção de um bioproduto a partir de insumos e matérias-primas obtidas de fontes naturais. Foram obtidos emulsões corporais ou óleos corporais bifásicos, simulando as encontradas no comércio, com odores agradáveis, a partir da mistura de óleos vegetais de abacate e coco, óleos essenciais e hidrolatos de lavanda e canela, e adição do corante bixina, para tornar mais atrativo o aspecto visual dos bioprodutos. Os constituintes dos óleos essenciais foram identificados por CG-EM e os óleos vegetais e o corante bixina foram caracterizados por UV-Vis. A proposta metodológica para a obtenção do bioproduto visa o emprego de técnicas de separação e extração que independem do uso de equipamentos sofisticados para caracterização, sendo a característica odorífera dos óleos essenciais e vegetais suficientes para a implementação da proposta de prática aqui apresentada para a disciplina. De forma opcional sugeriu-se o uso de amostras comerciais de óleos essenciais e vegetais para comparação olfativa com os óleos obtidos experimentalmente. Além disso, as matérias-primas obtidas também podem ser utilizadas em outras aulas da disciplina, atendendo aos princípios de Química Verde, os óleos essenciais como amostras para aulas de Cromatografia em Camada Delgada (CCD) e os óleos vegetais para a produção de biodiesel. A proposta apresentada para a obtenção de um bioproduto também pode ser realizada para estudantes do ensino médio.

\section{REFERÊNCIAS}

1. Baser, K. H. C.; Buchbauer, G.; Handbook of essential oils: Science, technology and applications, $2^{\text {nd }}$ ed., CRC Press: Boca Raton, 2016.

2. Spitzer, C. M. O. S. V. Em Farmacognosia da planta ao medicamento; Simões, C. M. O., Schenkel, E. P., Gosmann G., Mello, J. C. P., Mentz, L. A., Petrovick, P. R., eds.; $5^{\text {a }}$ ed., Editora da UFRGS/ Editora da UFSC: Porto Alegre/Florianópolis, 2004.

3. Craveiro, A. A.; Queiroz, D. C.; Quim. Nova 1993, 16, 224.
4. http://portal.anvisa.gov.br/documents/33880/2568070/RDC_271_2005. pdf/b51df869-921a-412e-92d9-c1626871f383/, acessada em janeiro 2021.

5. McMurry, J.; Química Orgânica, $3^{\mathrm{a}}$ ed., Cengage Learning: São Paulo, 2016.

6. Vianni, R.; Braz-Filho, R.; Quim. Nova 1996, 19, 400.

7. Moretto, E.; Fett, R.; Tecnologia de óleos de gorduras vegetais na indústria de alimentos, Varela: São Paulo, 1998.

8. Ramalho, H. F.; Suarez, P. A. Z.; Rev. Virtual Quim. 2013, 5, 2.

9. Bizzo, H. R.; Hovell, A. M. C.; Rezende, C. M.; Quim. Nova 2009, $32,588$.

10. Pavlacková, J.; Kovacsová, K.; Radimersky, P.; Egner, P.; Sedlariková, J.; Mokrejs, P.; Braz. J. Pharm. Sci. 2018, 54, 1.

11. De Oliveira, L. C.; Bloise, M. I.; Cosmet. Toiletries 1995, 7, 30.

12. https://abihpec.org.br/publicacao/caderno-de-tendencias-2019-2020/, acessada em janeiro 2021.

13. https://abihpec.org.br/anuario-2019/mobile/index.html\#p=1, acessada em janeiro 2021.

14. Victor, M. M.; Leite, J. L.; Ramos, G. S.; David, J. M; Cardoso, K. V.; Quim. Nova 2020, 43, 1522.

15. Cunha, S.; Rodrigues, M. C.; Mattos, R. R.; Teixeira, L. S. G.; Santos, A. O.; Santos, E. V.; Souza, R. S.; Andrade, G. S.; De Paula, R.; Jesus, D. S.; Quim. Nova 2018, 41, 691.

16. Cunha, S.; Matos, J. M.; Quim. Nova 2017, 40, 1253.

17. Cunha, S.; Lustosa, D. M.; Conceição, N. D.; Fascio, M.; Magalhães, V.; Quim. Nova 2012, 35, 638.

18. Silva, R. S.; Ribeiro, C. M. R.; Borges, M. N.; Blois, G. S. O.; Quim. Nova 2009, 32, 2234.

19. Costa, C. L. S.; Chaves, M. H.; Quim. Nova 2005, 28, 149.

20. Zeraik, M. R.; Yariwake, J. H.; Quim. Nova 2008, 31, 1259.

21. Brasil. Ministério da Saúde. Agência Nacional de Vigilância Sanitária. Formulário nacional da farmacopeia brasileira, $2^{\mathrm{a}}$ ed., Anvisa: Brasília, 2012.

22. Pianovski, A. R.; Vilela, A. F. G.; Silva, A. A. S.; Lima, C. G.; Silva, K. K.; Carvalho, V. F. M.; Musis, C. R.; Machado, S. R. P.; Ferrari, M.; Braz. J. Pharm. Sci. 2008, 44, 249.

23. Beni, M.; Cosmet. Toiletries 2013, 25, 34.

24. Sakamato, K.; Lochhead, R. Y.; Maibach, H. I.; Yamashita, Y.; Cosmestic science and technology: Theoretical principles and applications, $1^{\text {th }}$ ed., Elsevier Inc: Amsterdam, 2017.

25. Oliveira, S.; Moraes, C. A. P.; Brazilian Journal of Natural Sciences 2019, 2, 127.

26. Zubrick, J. W.; Manual de sobrevivência no laboratório de química orgânica, $6^{\mathrm{a}}$ ed., LTC: Rio de Janeiro, 2005.

27. Dias, A. G.; Costa, M. A.; Guimarães, P. I. C.; Técnicas de laboratório. Guia prático de química orgânica, $1^{\mathrm{a}}$ ed., vol. 1, Interciência: Rio de Janeiro, 2004.

28. Lide, D. R.; CRC Handbook of chemistry and physics, $87^{\text {th }}$ ed., Taylor and Francis: Boca Raton, 2006. 
29. Zheljazkov. V. D.; Cantrell, C. L.; Astatkie, T.; Jeliazkova, E.; J. Oleo Sci. 2013, 62, 195 .

30. Koketsu, M.; Gonçalves, S. L.; Godoy, R. L. O.; Lopes, D.; Morsbach, N.; Ciênc. Tecnol. Aliment. 1997, 17, 281.

31. Upson, T.; Andrews, S.; The genus Lavandula, $1^{\text {th }}$ ed., Royal Botanic Gardens: Kew, 2004.

32. Touati, B.; Chograni, H.; Hassen, I.; Boussaid, M.; Toumi, L.; Brahim, N. B.; Chem. Biodiversity 2011, 8, 1560.

33. Justus, B.; Almeida, V. P.; Gonçalves, M. M.; Assunção, D. P. S. F.; Borsato, D. M.; Arana, A. F. M.; Maia, B. H. L. N. S.; Paula, J. F. P.; Budel, J. M.; Farago, P. V.; Braz. Arch. Biol. Technol. 2018, 61, e18180111.

34. Aprotosoaie, A. C.; Gille, E.; Trifan, A.; Luca, V. S.; Miron, A.; Phytochem. Rev. 2017, 16, 761.

35. Almeida, M. R.; Martinez, S. T.; Pinto, A. C.; Rev. Virtual Quim. 2017, 9, 1117.

36. Kumar, S.; Kumari, R.; Open Access J. Sci. 2019, 3, 13.

37. Embrapa Amazônia Oriental; A cultura do urucum, $2^{\text {a }}$ ed. rev. ampl., Embrapa Informação Tecnológica: Brasília, DF, 2009.

38. Yabiku, H. Y.; Takahashi, M. Y.; Rev. Inst. Adolfo Lutz 1992, 52, 31.

39. Tocchini, L.; Mercadante, A. Z.; Ciênc. Tecnol. Aliment. 2001, 21, 310.

40. Garcia, C. E. R.; Bolognesi, V. J.; Dias, J. F. G.; Miguel, O. G.; Costa, C. K.; Cienc. Rural 2012, 42, 1510.

41. http://www.fruticultura.iciag.ufu.br/abacate.html, acessada em janeiro 2021.

42. Soares, H. F.; Ito, M. K.; Rev. Ciênc. Méd. 2000, 9, 47.

43. Tango, J. S.; Turatti, J. M. Em Abacate: Cultura, matéria-prima, processamento e aspectos econômicos; Instituto de Tecnologia de Alimentos, ed.; ITAL: Campinas: ITAL, 1992.

44. Tango, J. S.; Carvalho, C. R. L.; Soares, N. B.; Rev. Bras. Frutic. 2004, 26, 17.

45. Mooz, E. D.; Gaino, N. M.; Shimano, M. Y. H.; Amancio, R. D.; Spoto, M. H. F.; Ciênc. Tecnol. Aliment. 2012, 32, 274.

46. Salgado, J. M.; Danieli, F.; Regitano-D'arce, M. A. B.; Frias, A.; Mansi, D. N.; Ciênc. Tecnol. Aliment. 2008, 28, 20.

47. Lucchesi, A. A.; Montenegro, H. W. S.; An. Esc. Super. Agric., "Luiz de Queiroz”, Univ. São Paulo 1975, 32, 339.

48. Araujo, T. S.; Souza, S. O.; Sci. Plena 2008, 4, 114807.
49. Flor, J.; Dayolos, M. R.; Correa, M. A.; Quim. Nova 2007, 30, 153.

50. Yildirim, K.; Kostem, A. M.; Eur. Sci. J. 2014, 2, 425.

51. Korac, R. R.; Khambholja, K. M.; Pharmacogn. Rev. 2011, 5, 164.

52. Michalun, V.; Dinardo, J. C.; Skin care and cosmetic ingredients dictionary, $4^{\text {th }}$ ed., Cengage Learning: United States, 2014.

53. Kaur, C. D.; Saraf, S.; Pharmacogn. Res. 2010, 2, 22.

54. Lima, E. B. C.; Sousa, C. N. S.; Meneses, L. N.; Ximenes, N. C.; Santos Júnior, M. A.; Vasconcelos, G. S.; Lima, N. B. C.; Patrocínio, M. C. A.; Macedo, D.; Vasconcelos, S. M. M.; Braz. J. Med. Biol. Res. 2015, 48, 953.

55. Kumar, S. N.; J. Agric. Food Chem. 2011, 59, 13050.

56. Aragão, W. M.; Cruz, E. M. O.; Tavares, M.; Ribeiro, F. E.; Tupinambá, E. A.; Pimentel, S. A.; Takemoto, E.; 2004 Rev. Inst. Adolfo Lutz 2004, $63,159$.

57. Laureles, L. R.; Rodriguez, F. M.; Reano, C. E.; Santos, G. A.; Laurena, A. C.; Mendonza, E. M. T.; J. Agric. Food Chem. 2002, 50, 1581.

58. DebMandal, M.; Mandal, S.; Asian Pac. J. Trop. Med. 2011, 4, 214.

59. Chioma, O.; Alexander, O.; Ugochi, K.; Erasmus, A.; Melford, E.; Innocencia, C.; Joshua, U.; Ifeanyi, O.; Chidi, E.; Journal of Scientific Research \& Reports 2020, 26, 104.

60. Sulaiman, S.; Aziz, A. R. A.; Aroua, M. K.; J. Food Eng. 2013, 114, 228.

61. Adeyanju, J. A.; Ogunlakin, G. O.; Adekunle, A. A.; Alawode, G. E.; Majekolagbe, O. S.; J. Chem. Pharm. Res. 2016, 8, 374.

62. Lenardão, E. J.; Freitag, R. A.; Dabdoub, M. J.; Batista, A. C. F.; Silveira, C. C.; Quim. Nova 2003, 26, 123.

63. Bramé, D. B.; Tininis, A. G.; $1^{\circ}$ Congresso Sul-Americano de Resíduos Sólidos e Sustentabilidade, Gramado, Brasil, 2018.

64. Sani, I.; Owoade, C.; Abdulhamid, A.; Fakai, I. M.; Bello, F.; Int. J. Adv. Res. Chem. Sci. 2014, 1, 22.

65. Patil, U.; Benjakul, S.; J. Food Sci. 2018, 83, 2019.

66. Osman, A. Em Fruits oils: Chemistry and Functionality; Ramadan, M. F. ed.; Springer: Switzerland, 2019, cap. 9.

67. Argawal, R. K.; Bosco, S. J. D.; MOJ Food Processing \& Technology 2017, $4,54$.

68. Ndife, J.; Obot, D.; Abasiekong, K.; Asian Food Science Journal 2019, 8,1 .

69. Kumar, K. A.; Viswanathan, K.; J. Spectrosc. 2013, 2013, 1.

70. Widiyati, E.; AIP Conf. Proc. 2017, 1868, 020004. 